\title{
THE IMPACT OF SELF-ADJUSTMENT ON ACADEMIC ACHIEVEMENT OF THE STUDENTS
}

\author{
Augusto da Costa, Fattah Hanurawan, Adi Atmoko, Immanuel Hitipeuw* \\ Instituto Superior Cristal, Dili Timor Leste
}

\begin{tabular}{ll} 
A R T I C L E I N F O & A B S T R A C T \\
\cline { 2 - 3 } $\begin{array}{l}\text { Keyword: } \\
\text { self-adjustment } \\
\text { academic achievement }\end{array}$ & $\begin{array}{l}\text { The purposes of this research is to discover the impact of self-adjustment on student } \\
\text { academic achievement. The method that used in this study is a correlational study with } \\
\text { random sampling. The subject of the research is Timorese student is studying in Indonesia, } \\
\text { there are } 180 \text { samples. The data collection has used a scale of Likert. The date is analyzed } \\
\text { with simple correlation. The result showed there is } 46.1 \% \text { of significant and positive } \\
\text { correlation of self-adjustment on student academic achievement. It means if self- } \\
\text { adjustment being conducted well, student academic achievement will increase. } \\
\text { Keywords: self-adjustment, academic achievement }\end{array}$
\end{tabular}

\section{INTRODUCTIONS}

Timor Leste is a new country in Asian has greatest challenges in relating to the human resources in developing a process of the country. The human resources(Mcmillan \& Morris, 2012) become mind challenges for the country because after the early days of independent there very few numbers of Timorese have good education qualified to build the country. The Good human resources are achieved by the good education system(Alwell, Cobb, \& Alwell, 2009). In the 21st century, education is a fundamental element for developing human resources each country human resources throughout the globe (Watson \& Odendaal, 2013)including of Timor Leste. Human resources facilitate the Timorese government to explore and to utilize its natural resources to develop all living sectors (Lucas et al., 2015; Ministry, 2015; To elevate human resources of the student, The Timorese Government has established a UniversidadeNational de Timor-Leste and 10 private institutes and universities. These universities to facilitate, to strengthen and to obtain: the goals of the country which is including, social, politics, education, culture, health and believing system, (Macpherson, 2011).

These goals are rooted in the National Constitution that recognizes and guarantees: (1) the right to education and culture of each one; (2) each citizen facilities for education and training, (3) public and private education institutions is recognized, (4) access of each citizen, according to their ability of higher education, scientific research and creative artistic. Over more, Timorese government established cooperation with the neighboring country in the area of education to increase through education(Leste, 2002; Flanz, 2018).

One of the Timor Leste's neighborhood country that has tie relationship in education in Indonesia. Since 2002 Indonesia government open it education gate for Timorese student through the diplomatic relationship of both countries. Since then till now, Timorese student is studying in the universities and at the various faculties, the human resources through the main education cite in Indonesia. Based on the result of previous research showing that there 39\% (Da Costa, 2015) of Timorese students have postponed their graduation or needs additional semester for concluding their study. Those prolongers student achieved academic achievement at medium levels between $2.50-2.75$ are $39.71 \%$.

\footnotetext{
"Corresponding author.

E-mail addresses: augusto.costa.1501119@students.um.ac.id (Augusto da Costa), fhanurawan@yahoo.com (Fattah Hanurawan), adi.atmoko.fip@um.ac.id (Adi Atmoko), imanuel.hitipeuw.fip@um.ac.id (Immanuel Hitipeuw)
}

ISSN : 2597-7385 (Online) - ISLLAC : Journal of Intensive Studies on Language, Literature, Art, and Culture is licensed under Creative Commons Attribution-ShareAlike 4.0 International License (http://creativecommons.org/licenses/BY/4.0/).

1 | ISLLAC : Journal of Intensive Studies on Language, Literature, Art, and Culture 
Based on the observation there is an indication that Timorese student is struggling to do selfadjustment to the social, culture and the learning ethos of the local people. There is an indication that Timorese student is always established their group and gathering with their own people. The groups are established on district-based or organizational based, means the members of the groups come from the same district or same organization that has been existed in Timor Leste(Rubrico, 2015)

This fact limits them to enlarge their relationship with the new society, even on the campus. On the other hand, the International student needs to adjust them self to the local environment. This adjustment presume helps the international student to learn effectively. Has been (Muller, 2011) mentioned that International student needs help to adjust and to develop the programs any activities to promote the learning especially in using of the English language (Kuhn \& Müller, 2014).

It means the international students need to adjust into social and academic adjustment. Social and academic adjustment is enabling the student to reach an optimal academic achievement (Morse, 2016). There are the human resources was main questions can be asked beyond the above explanation, such as what is the academic achievement? How is an important academic achievement for the Timorese student? What is the self-adjustment and how self-adjustment impacts of academic achievement?

\section{LITERATURE REVIEW}

Academic Achievement

Academic achievement is the level of knowledge and skill achieved by students in reaching the learning goals. Academic achievement consists of the results of annual exams. Academic achievement is one the indicators of student ability to complete the task. The forms of the learning completion are indicated in the great point academic. The grade point academic is composed of points and values of the previous semester. It becomes one of the main element to measure the student's skills and knowledge quality. The grade point academic also contributes to the quality standard of education system and institution (Farooq, et al., 2011; Ray, 2011; Farrington et al., 2012; Garcia \& Al-Safadi, 2014; Bhagat, 2017).

Academic achievement becomes a measurement of the quality of student's skills and knowledge means the student who has high skills and broad knowledge, it will express in academic achievement. It means academic achievement is expressing of those students' human resources through weekly, monthly and semester examination marks or value. The values of the examination are formed by letter or number. It considers as the most important factor in predicting academic ability (Koning et al., 2012). Grade point academic is most important point including levels of students IQ for the student to continue the further level of tertiary education (Kaufman et al., 2012) or to obtain the passion on the workplace.

Academic achievement becomes the most desirable of all institution leaders including lecturers and professor in the university. Academic achievement is indicating the students have increased whether in their knowledge and skill or not yet. The lecturers used various methods to evaluate their students' knowledge and skill(Gholami, Asli, Nazari-, \& Noruzy, 2013). Those students knowledge and skill that have been tried to develop by many ways including studying to discover which variables that has impacted to students learning in order to improve related and relevant factors that were the most effective to the student academic achievement (Srisongkhuman, 2014). The previous study showed that academic achievement is impacted by self-adjustment to the new environment of all elements in the campus (Kudari, 2016). It means self-adjustment becomes an important element of academic achievement.

\section{Self-adjustment}

Adjustment is expression and process of an individual attitude in conjunction with self and its environment to create a balance and harmonious. Adjustment is defined as a process of altering the individual behavior to obtain a harmonious relationship with their environment. This response brought some types of change that are taken place. This changing may raise an unhappy because of one to try to perform a new type of balancing and homeostasis between the individual and its environment (Mudasir\&Gannaie, 2013).

Adjustment is understood as the one's meeting of its psychological and behavioral demands and accepting oneself. It means adjustment as an expression of the one's ability to fulfill its psychological and behavioral needs in regards to self-acceptance as well as inclusiveness in circumstances of life, endearing of social acceptance and participation in community activities with balancing and harmonies. Psychological process of adjustment is understood as struggling of affection and feeling to adjust oneself to the environment demands and the needs to be accepted and to be recognized among the others. The behavioral process of adjustment is more understood as attitudes and behavior and the technique to overcome a challenging situation. It will enable one to fulfill its needs, to reduce challenges as well as to satisfy the motives and to obtain achievement of balancing and satisfaction. Furthermore, the adjustment is 
formulated as the behavioral process by a human to defend an equilibrium among its various needs and challenges of its environments and circumstances (Al-khatib et al., 2012). It means adjustment is an essential element of social life.

Social adjustment is formulated as a psychological process. It frequently involves imitating with new standards and values of the attitudes and a way of life. Social adjustment is expressed among invidious as a member of society. As social beings one lives in a society, one can be formed opinions about others and the other ways. Everyone expects of acceptance and valued from and within a society (Mudasir\&Gannaie, 2013).

In terms of education, an international student needs to adjust them self to the new social environment including campus as well as society. There are five areas that challenge international students to experience adjustment issues. Such as academic, physical health, financial, vocational and personal/social. International students face adjustment psychologies and behaviors problems (Gebhard, 2012)(Mobility, 2012).

International students encountered human resources the main area's problems in adjustments such as academic, social interaction, and emotional reaction to novel environment and circumstance. The adjustment problems appear because of language barriers, unfamiliarity with available resources and the way to access those resources. International student face lack of an established social support system and social network grounded the problems is experienced in those areas including depression, loneliness and isolation from the relationship (Smith \&Khawaja, 2011; Mesidor\& Sly, 2016) it happen because they feel indirect social rejection (Sebastian, 2015; Busch et al., 2016).

The international student faces stressful experiences because of loss-cross culture means they struggle to adjust and to let their familiar richness of things (personal relationships, home, family, country, and educational system environment) gone from them. At the same time, international student struggles to adjust to a new culture, society, environment and new circumstance including learning and academic ethos (Wang et al., 2015). Meanwhile, they struggle to embrace new people, culture, society, and environment in the positive mainstream because all these experiences enrich them to be a flexible person to increase social, academic, self-efficacy, psychology and cultural adjustment and create a spirit of acculturation(Smith \& Khawaja, 2011). Adjustment refers to the multi-dynamic processes that are ultimately lead to the achievement of an appropriate match between the one and the environment including academic achievement. The key adjustment problems faced by the international students are four factors: general living, socio-cultural, academic and personal psychological adjustment (Malaklolunthu\&Selan, 2011; Mustaffa, \&Ilias, 2013).

The positives impacts of adjustment for the international student is enlarged and enrich their living experiences, including study. The study aspect of the novel environment they get numbers of education facilities including, library and other learning media, qualified lecturers and professors. They build a new and effective relationship with their peers or new classmate that has their own richness of academically experiences. Those new experiences open opportunities for the International student to achieve more knowledge and skill in direction of academic achievement (Nasir, 2012). In this understanding, Timorese student is studying in Indonesia has the same experience.

Timorese students struggle to face the same experiences of the international student in general. They experienced depression, loneliness, and isolation that impact on the study and academic achievement. On the other hand, Timorese student also gets new experiences that open new and large and broad opportunities for them to achieve more knowledge and skill in direction of academic achievement. It means the Timorese student in Indonesia supposed to achieve an optimal academic achievement.

\section{METHOD}

This study method was used to discover the impact of the Timorese student self-adjustment on academic achievement was a correlational study with a quantitative umbrella, the participant is 180 samples from the 4.500 Timorese students are studying in Indonesia from the academicals year of 2016/2017. Hair et al. (2013) suggest that sample size can be driven by the following factors in a structural equation model design: the significance level (5\%,) a statistical power of $80 \%$, and R2 values of at least 0.25 . It means the sample size is 100-300.

The sample of the research was selected by random sampling. The date is collected with 8 items the outcome of 24 items the initial items. The survey questionnaire was established by research based on grille instrument. It has been tested by experts and field testing with 120 sample and it been analyzed with exploratory factor analysis $(\geq 0.54)$ and confirmatory factor analysis $(\geq 0,701)$. It is according to hair et al., (2006) the instrument that established by research human resources through field and expertise tested at least reach the minimum point of analysis factor exploratory is 0.30 and points of confirmatory factor 
analysis is 0.50 or so. In regards to academic achievement is discovered from the printout of the study result of all the semester that has been concluded.

\section{FINDINGS}

The result of the data analysis as displayed in table 1 that correlation between self-adjustment and grade points academic is significant $0.00<0.05$ and the value of correlation is 0,461 .

Table 1 Correlations

\begin{tabular}{|c|c|c|c|}
\hline \multicolumn{4}{|c|}{ Correlations } \\
\hline & & GPA & SA \\
\hline \multirow[t]{3}{*}{ GPA } & $\begin{array}{l}\text { Pearson } \\
\text { Correlation }\end{array}$ & 1 & $0.461^{* *}$ \\
\hline & Sig. (2-tailed) & & 0.000 \\
\hline & $\mathrm{N}$ & 180 & 180 \\
\hline \multirow[t]{3}{*}{ SA } & $\begin{array}{l}\text { Pearson } \\
\text { Correlation }\end{array}$ & $0.433^{* *}$ & 1 \\
\hline & Sig. (2-tailed) & 0.000 & \\
\hline & $\mathrm{N}$ & 180 & 180 \\
\hline
\end{tabular}

Source: output of correlations analysis

Notes: $\mathrm{GPA}=$ grade point academic, $\mathrm{SA}=$ self-adjustment

Table 2 Criteria for correlation degree Table 2 Criteria of correlation degree

\begin{tabular}{|l|l|l|l|}
\hline No & value of pearson correlation & $0,00-0,20$ & uncorrelated \\
\hline 1 & value of pearson correlation & $0,21-0,40$ & week correlated \\
\hline 2 & value of pearson correlation & $0,41-0,60$ & moderate correlated \\
\hline 3 & value of pearson correlation & $0,61-0,80$ & strong correlated \\
\hline 4 & value of pearson correlation & $0,81-1,00$ & perfect correlated \\
\hline
\end{tabular}

Source: created by research (2018)

The purposes of the correlation test are to know relationship level between variable $\mathrm{X}$ and $\mathrm{Y}$ which is formulated by the correlation coefficient $(r)$. There are two criteria to decide whether the correlation is significant or no. The first, if the value of significant is $\leq 0.05$ means correlated. Second, if the value of significant is $>0.05$ means uncorrelated.

\section{DISCUSSIONS}

The table 1 shows that self-adjustment significant value is 0.00 to the grade point academic. The value of correlation between self-adjustment and grade point of academic is 0,461 . Reflected on the criteria of significance can be formulated that correlation between self-adjustment and grade point academic is significant with the value of significant $0.00<0.05$. The table 1 shows that the correlation values of selfadjustment to grade point academic is 0,461 . Furthermore, look at table 2 is described that score of the correlation between $0.41-0.60$ is a moderate correlation. Moderate correlation is between a week and stronger correlation. It notified that the correlation between self-adjustment and grade point academic is 46.1\%.

This percentage is enough indicated that grade point academic of Timorese student is studying in Indonesia has been impacted by self-adjustment. This finding is on the same truck or direction of previous research that conducted by Wang et al., (2015) that international student needs to adjust them self to a new culture, society, environment and new circumstance including learning and academic ethos. It will facilitate them to reach an optimal grade point academic. The finding also fortified the previous research that was conducted by Nasir (2012) those new experiences open new opportunities for the International student to achieve more knowledge and skill in direction of academic achievement.

Based on this finding and the previous finding can be formulated that self-adjustment has impacted on Timorese grade point academic. It means to elevate Timorese academic achievement in their study, needs to accompany Timorese student to effectively adjust them self to the new environment, social and cultures, psychology and the new ethos of learning. 


\section{CONCLUSIONS}

Based on this finding can be concluded that Timorese grade point academic has been impacted $46.1 \%$ by their self-adjustment. Therefore the academic achievement of Timorese student was studying in Indonesia was impacted by self-adjustment. Moreover, if self-adjustment of the Timorese was implementing well in their daily life; it will elevate and increase their academic achievement otherwise if on the contrary ways their academic will stagnate too. So to elevate academic achievement needs to handle well self-adjustment.

\section{REFERENCES}

Alwell, M., Cobb, B., \& Alwell, M. (2009). Career Development for Exceptional Individuals Functional Life Skills Curricular Interventions for Youth With Disabilities A Systematic Review. https://doi.org/10.1177/0885728809336656.

Al-khatib, Bilal, A., Habis, S., F. S. S. A. (2012). Student's Adjustment to College Life at Albalqa Applied University Albalqa Applied University, 2(11), 7-16.

Bhagat, P. (2017). Relationship Between Self- Esteem And Academic Achievement Of Secondary School Students, 6(4).

Busch, V., Loyen, A., Lodder, M., Augustinus, J. P., \& Yperen, T. A. Van. (2016). The Effects of Adolescent Health-Related Behavior on Academic Performance: A Systematic Review of the Longitudinal Evidence, $X X(X), 1-30$.

Constitution of, C., Democratic, T. H. E., \& Of, R. (2002). Constitution Of The Democratic Republic TimorLeste. Timor Leste: Dili

Flanz, G. H. (2018). Timor-Leste's Constitution of.Leste, N. P. of R. D. of T. Constitution of The Democratic Republic Timor-Lesleste, The Democratic Republic Timor-Leste (2002).

Gholami, M. H., Asli, M. N., Nazari-, S., \& Noruzy, A. (2013). Investigating the Influence of Knowledge Management Practices on Organizational Performance : An Empirical Study, 10(2), 205-216.

Hafiz Mudasir, \& M. . G. (2013). Social and Personal Adjustment of Adolescents- A study of Higher Secondary Students of District Srinagar, 5(12), 164-171.

Hair, J. F., Hult, G. T. M., Ringle, C. M., \& Sarstedt, M. (2013). A Primer on Partial Least Squares Structural Equation Modeling (PLS-SEM). Thousand Oaks: Sage.

Kaufman, S.B., Reynolds, M.R., Liu, X., Kaufman, A.S., McGrew, K. S. (2012). Intelligence Are cognitive g and academic achievement $\mathrm{g}$ one and the same $\mathrm{g}$ ? An exploration on the Woodcock-Johnson and Kaufman tests. Intelligence, 0160-2896/.

Kudari, J. M. (2016). Survey on the Factors Influences the Students' Academic Performance. REsearch Scholar, 9359(6), 30-36.

Kuhn, J., \& Müller, A. (2014). Context-based science education by newspaper story problems : A study on motivation and learning effects \$. Perspectives in Science, 2(1-4), 5-21.

Lucas, M., Cabrita, I., \& Ferreira, A. (2015). Pathways to Change: Improving The Quality of Education in Timor- Leste. Procedia - Social and Behavioral Sciences, 186, 732-738.

Macpherson, R. (2011). Educational Administration and Management in Timor Leste Language And Capacity Building Challenges In A Post-Conflict Context, 25(2), 186-203.

Malaklolunthu, S., \& Selan, P. S. (2011). Adjustment problems among international students in Malaysian private higher education institutions. Procedia - Social and Behavioral Sciences, 15(1877-0428

Mcmillan, H. S., \& Morris, M. L. (2012). Advances in Developing Human Resources. https://doi.org/10.1177/1523422312455626.

Mesidor, J. K., \& Sly, K. F. (2016). Factors that Contribute to the Adjustment of International Students, G(1), 262-282.

Ministry, L. (2015). National Education.Timor Leste: Dili

Mobility, A. (2012). Journal of Studies in International Education. https://doi.org/ $10.1177 / 1028315311421842$

5 | ISLLAC : Journal of Intensive Studies on Language, Literature, Art, and Culture 
Morse, S. R. T. and A. (2016). THINGS, (Copyright @ 2016 by the National Association of Student Personnel Administrators (NASPA),), 12.

Muller, A. (2011). Addressing the English language needs of international nursing students. Journal of Academic Language \& Learning, 5, 14-22.

Mustaffa, C.S., Ilias, M. (2013). Relationship between students adjustment factors and cross cultural adjustment: A survey at the Northern University of Malaysia. Intercultural Communication Studies XXII, 1(1), 279-300.

Nasir, M. (n.d.). Effects of Cultural Adjustment on Academic Achievement of International Students, 22(2), 95-103.

Rubrico, J. G. U. (2015). Increasing Student Engagement and Retention Using Social Technologies Article information :Cutting-edge Technologies in Higher Education (Vol. 6). Emerald Group Publishing Ltd.

Sebastian, C. L. (2015). Psicología Educativa. Psicología Educativa, 21(2), 125-131.

Srisongkhuman resources am, W. (2014). The Effects of Learning Styles and other Psychological Variables on Predicting to Students' Academic Achievement Based on Learning Evaluation Method in Adolescent Problem and Guidance Class, 14(2), 1-26.

Smith, R. A., \& Khawaja, N. G. (2011). A review of the acculturation experiences of international students. International Journal of Intercultural Relations, 35(6), 699-713.

Smith, R. A., \& Khawaja, N. G. (2014). A group psychological intervention to enhance the coping and acculturation of international students. Advances in Mental Health. Journal of International Students 12(2), 110-124.

Wang, K.T, Wei, M., Zhoa, R., Chuang, C. \& Li, F. (2015). The cross- cultural loss: Development and psychometric evaluation. Psychological Assessment, 27(1), $42-53$

Watson, V., \& Odendaal, N. (2013). Education and Research Changing Planning Education in Africa: The Role of the Association of African. https://doi.org/ 10.1177/0739456X12452308.

6 | ISLLAC : Journal of Intensive Studies on Language, Literature, Art, and Culture 